\title{
FORMULASI SEDIAAN GEL MASKER WAJAH EKSTRAK ETANOL UMBI WORTEL (Daucus carofal)
}

\author{
Sylvia Puspita ${ }^{1}$ Arikha Ayu Susilowati $^{2}$ \\ ${ }^{1}$ Program Studi DIII Farmasi, Stikes Bhakti Husada Mulia Madiun \\ ${ }^{2}$ Program Studi S1 Farmasi, Stikes Bhakti Husada Mulia Madiun \\ E-Mail: sylviapuspita@gmail.com
}

\begin{abstract}
ABSTRAK
Pemeliharaan kulit wajah memerlukan perhatian yang khusus karena kulit wajah merupakan organ yang sensitif terhadap perlakuan dan rangsangan. Tingginya paparan radikal bebas pada kulit dapat menyebabkan stress pada kulit. Sters pada kulit ini, akan mengakibatkan penyakit kanker kulit dan penuaan dini. Sediaan masker gel dengan berbagai macam basis yang ada dipasaran umumnya dikombinasi dengan bahan alam. Oleh karenanya, penlitian ini ingin mengetahui pada konsentrasi berapa konsentrasi formulasi masker gel ekstrak wortel dan memberikan stabilitas sediaan gel masker wortel yang baik. Penelitian ini termasuk dalam penelitian eksperimental dengan tujuan untuk mengetahui pengaruh konsentrasi Ekstrak wortel (Daucus carota $\mathrm{L}$ ) pada masker gel. Rancangan penelitian dilakukan dengan membuat Ekstrak wortel (Daucus carota L) pada berbagai konsentrasi $(2,5 \% ; 5 \% ; 7,5 \%)$ menggunakan pelarut etanol $70 \%$ dengan metode maserasi. Parameter yang dianalisis meliputi uji organoleptis, uji $\mathrm{pH}$, uji daya lekat, uji daya sebar, uji viskositas dan uji iritasi. Analisa data menggunakan uji One Way ANOVA. Berdasarkan hasil dalam penelitian dapat disimupulkan, bahawa formulasi gel masker dengan konsentrasi ekstrak wortel 5,0\% mempunyai hasil yang sangat baik pada hasil organeleptis, $\mathrm{pH}$, uji daya sebar, uji daya lekat, uji viskositas, uji kecepatan mengering dan uji stabilitas fisik gel.
\end{abstract}

Kata Kunci : Gel, Masker Wajah, Ekstrak Etanol Umbi Wortel

\begin{abstract}
Maintenance of facial skin requires special attention because facial skin is an organ that is sensitive to treatment and stimulation. High exposure to free radicals on the skin can cause stress on the skin. Sters on this skin, will lead to skin cancer and premature aging. Gel mask preparations with various bases on the market are generally combined with natural ingredients. Therefore, this research wants to find out at what concentration the concentration of the carrot extract gel mask formulation and provide good stability of the carrot mask gel preparation. This study was included in an experimental study with the aim to determine the effect of carrot extract (Daucus carota L) concentration on gel masks. The study design was carried out by making carrot extract (Daucus carota L) at various concentrations (2.5\%; 5\%; 7.5\%) using 70\% ethanol solvent with maceration method. The parameters analyzed include organoleptic test, pH test, stickiness test, spreadability test, viscosity test and irritation test. Data analysis uses the One Way ANOVA test. Based on the results of this research, it can be concluded that the gel mask formulation with 5.0\% carrot extract concentration has very good results on organeleptic yield, $\mathrm{pH}$, spreadability test, adhesion test, viscosity test, dry speed test and gel physical stability test.
\end{abstract}

Keywords $\quad$ : Gel, Facial Mask, Ethanol Extract Carrot Bulbs 
PENDAHULUAN

Indonesia memiliki kekayaan flora, banyak tanaman obat yang dipercaya dan banyak yang sudah dilakukan penelitian dalam berbagai manfaat. Pemeliharaan kulit wajah memerlukan perhatian yang khusus karena kulit wajah merupakan organ yang sensitif terhadap perlakuan dan rangsangan. Salah satu masalah saat ini yang berkaitan dengan kulit wajah yaitu penuaan dini. Antioksidan berfungsi untuk melindungi tubuh dari radikal bebas, baik secara endogen maupun eksogen. Bagian tubuh yang sering terpapar oleh radikal bebas secara eksogen adalah kulit, seperti sinar radiasi ultraviolet, dan asap rokok. Tingginya paparan radikal bebas pada kulit dapat menyebabkan stress pada kulit. Sters pada kulit ini, akan mengakibatkan penyakit kanker kulit danpenuaan dini (Barrel et al., 2001).Sediaan masker gel dengan berbagai macam basis yang ada dipasaran umumnya dikombinasi dengan bahan alam.

Filtrat perasan wortel (Daucus carota, Linn.) yang mengandung beta karoten. Peran penting beta karoten di dalam tubuh yaitu sebagai prekursor vitamin A dan sebagai antioksidan. Beta karoten sebagai antioksidan digunakan untuk pencegahan dan pengobatan penyakit yang berhubungan dengan stress oksidatif, sehingga dapat digunakan sebagai alternatif dalam pembuatan sunscreen karena bersifat antioksidan sehingga dapat mengurangi kerusakan oksidatif akibat ROS.

Sediaan gel yang baik dapat diperoleh dengan cara memformulasikan beberapa jenis bahan pembentuk gel, namun yang paling penting untuk diperhatikan adalah pemilihan gelling agent, yaitu suatu bahan yang digunakan untuk menjaga konsistensi cairan dan padatan dalam suatu bentuk gel. Beranjak dari permasalahan di atas, maka penelitian ini difokuskan pada permasalahan pada konsentrasi berapa formulasi terbaik masker gel ekstrak wortel dan bagaimana stabilitas sediaan gel masker wortel sebagai bahan informasi dan edukasi kepada masyarakat luas.

\section{METODE PENELITIAN}

Penelitian ini termasuk dalam penelitian eksperimental dengan tujuan untuk mengetahui pengaruh konsentrasi Ekstrak wortel (Daucus carota L) pada masker gel. Rancangan penelitian dilakukan dengan membuat Ekstrak wortel (Daucus carota L) menggunakan pelarut etanol $70 \%$ dengan metode maserasi. Parameter yang dianalisis meliputi uji organoleptis, uji $\mathrm{pH}$, uji daya lekat, uji daya sebar, uji viskositas dan uji iritasi. Penelitian dilakukan di Laboratorium Kimia Terpadu dan Laboratorium Farmasetika STIKES Bhakti Husada Mulia 
Madiun, Jalan Taman Praja, Kecamatan Taman, Madiun. Alat yang digunakan dalam penelitian ini meliputi neraca analitik (OHAUS), beaker glass (IWAKI), alumunium foil, mortir dan stamfer, batang pengaduk, pipet tetes, corong, penangas air (FAITHFULL), cawan porselen, wadah sediaan gel, $\mathrm{pH}$ meter, alat uji daya lekat, alat uji daya sebar (ekstensometer), viskometer Brookfield dan stopwatch (KENKO). Bahan yang digunakan dalam penelitian ini meliputi ekstrak wortel (Daucus carota L), NaCMC, PVA, propilenglikol, nipagin, aquades dan etanol $70 \%$.

Evaluasi stabilitas fisik sediaan, yaitu organoleptis, pengukuran $\mathrm{pH}$, daya sebar, daya lekat dan viskositas. Data yang didapatkan dari penelitian ini dianalisis berdasarkan uji yang dilakukan dengan mendeskripsikan hasil uji organoletis dan uji iritasi dari sediaan serta menganalisis hasil uji pH, uji daya lekat, uji daya sebar dan uji viskositas secara statistika menggunakan program SPSS 20.0 yaitu uji One Way ANOVA dengan taraf kepercayaan $95 \%$.

\section{HASIL DAN PEMBAHASAN}

Kombinasi CMC-NA dan PVA sebagai gelling agent karena PVA akan membuat gel mengering cepat tanpa harus menambahkan bahan lain seperti alkohol serta membentuk lapisan film atau pell off yang kuat dan plastis sehingga memberikan kontak yang baik pada kulit ( Resko et el, 2007). Gel yang terbentuk dikarenakan adanya jebakan cairan yang di perantarai oleh basis gel seperti CMC-Na. Gelling agent ini menggunakan sistem dispersi hidrokoloid dalam pembentukan gel. Gel hidrokoloid terjadi karena adanya pembentukan jala atau jaringan berbentuk tiga dimensi oleh gelling agent yang terbentuk dengan mengikat fase air oleh ikatan hidrogen.

Interaksi pembentukan ikatan hidrogen diperkirakan diperantarai oleh adanya gugus hidroksil (-OH) dan gugus karbonil $(\mathrm{C}=\mathrm{O})$ yang ada pada gelling agen dengan air dan bahan lainnya. Semakin banyak ikatan hidrogen yang terjadi maka akan semakin kuat ikatan yang terbentuk sehingga viskositas akan tinggi.

Material PVA merukan suatu polimer organik sintetik dari bahan polivinil asetat dengan sifat dapat terlarutkan di dalam air, PVA sangat mudah mengembang jika berinteraksi dengan air dikarenakan gugus aktif PVA berupa Hidroksil (-OH). Begitu pula dengan CMC$\mathrm{Na}$ yag memiiki gugus Hidroksil $(-\mathrm{OH})$ yang menjadikan kedua gelling agent bersifat Hidrofilik.

Pada formula masker gel peel off ditambahkan propilenglikol, fungsinya sebagai humektan yang dapat mencegah kehilangan zat pembawa dari sediaan 
sehingga dapat mencegah proses sineresis.

Untuk mencegah timbulnya

\section{Organoleptis}

mikroorganisme seperti bakteri dan jamur ditambahkan pengawet metil paraben dan propil paraben yang dikombinasi agar meningkatkan efeknya sebagai agen antibakteri dan jamur.

Pengujian organoleptis adalah pengujian yang didasarkan pada proses pengindraan yang meliputi pengamatan pada warna, bau konsistensi (Sayuti., 2015). Hasil pengujian organoleptis gel:

Tabel 1 Hasil Uji Organoleptis

\begin{tabular}{cllc}
\hline Formulasi & Warna & \multicolumn{1}{c}{ Aroma } & Konsistensi \\
& & & \\
\hline FI & Orange & Khas simplisia wortel & Agak kental \\
\hline FII & Orange & Khas simplisia wortel & Kental \\
\hline FIII & Orange & Khas simplisia wortel & Sangat kental \\
\hline
\end{tabular}

\section{Pengujian pH}

Pengujian $\mathrm{pH}$ adalah pengujian derajat keasaman dari sediaan yang diformulasikan (Sayuti, 2015). Uji pH dilakukan untuk melihat tingkat keasaman sediaan gel untuk menjamin sediaan gel tidak menyebabkan iritasi pada kulit.pH sediaan gel diukur dengan menggunakan $\mathrm{pH}$ meter. $\mathrm{pH}$ sediaan yang memenuhi kriteria $\mathrm{pH}$ kulit yaitu dalam interval 4,5-7.

Tabel 2 Hasil Pengukuran pH

\begin{tabular}{cccccccc}
\hline Formulasi & \multicolumn{7}{c}{ Hasil Pengukuran pH } \\
\cline { 2 - 7 } & $\mathbf{1}$ & $\mathbf{2}$ & $\mathbf{3}$ & $\mathbf{4}$ & $\mathbf{5}$ & $\overline{\mathbf{x}} \pm$ SD & Sig. \\
\hline FI & 6,90 & 6,87 & 6,89 & 6,91 & 6,84 & $6,88 \pm 0,0277$ & 0,000 \\
\cline { 2 - 7 } FII & 6,87 & 6,89 & 6,90 & 6,84 & 6,90 & $6,89 \pm 0,0278$ & \\
\hline FIII & 6,79 & 6,81 & 7,00 & 6,70 & 6,90 & $6,84 \pm 0,0730$ & \\
\hline
\end{tabular}

Pengukuran $\mathrm{pH}$ menunjukkan bahwa derajat keasaman sediaan gel setiap formulasi berbeda. Formulasi I memiliki pH sediaan antara 6,84-6,91. Formulasi II memiliki pH sediaan antara 6,84-6,90. Formulasi III memiliki pH sediaan antara 6,70-7,00. Hal tersebut menunjukkan bahwa $\mathrm{pH}$ sediaan Formulasi I, II dan III sesuai dengan ketentuan, yaitu sesuai dengan $\mathrm{pH}$ kulit 4,5-7.

\section{Uji Daya Sebar}

Pengujian daya sebar adalah untuk mengetahui kemampuan gel untuk menyebar apabila diaplikasikan ke kulit. Uji daya sebar dilakukan untuk menjamin pemerataan gel saat diaplikasikan pada kulit yang dilakukan 
segera setelah gel dibuat. Daya sebar gel

yang baik antara 5-7 cm.

Tabel 3. Hasil Uji Daya Sebar

\begin{tabular}{cccccccc}
\hline Formulasi & \multicolumn{7}{c}{ Hasil Uji Daya Sebar (cm) } \\
\cline { 2 - 7 } & $\mathbf{1}$ & $\mathbf{2}$ & $\mathbf{3}$ & $\mathbf{4}$ & $\mathbf{5}$ & $\overline{\mathbf{x}} \pm$ SD & Sig. \\
\hline FI & 6,12 & 6,16 & 6,20 & 6,17 & 6,25 & $6,18 \pm 0,0485$ & 0,000 \\
\cline { 2 - 6 } FII & 5,23 & 5,25 & 5,22 & 5,25 & 5,19 & $5,23 \pm 0,0238$ & \\
\cline { 1 - 6 } FIII & 4,29 & 4,15 & 4,18 & 4,22 & 4,31 & $4,23 \pm 0,0689$ &
\end{tabular}

Formulasi I memiliki daya sebar rata-rata $6,18 \mathrm{~cm}$. Formulasi II memiliki daya sebar rata-rata $5,23 \mathrm{~cm}$. Formulasi III memiliki daya sebar rata-rata 4,23 cm. Hasil uji menunjukkan bahwa signifikansi daya sebar sebesar 0,000 ( $\rho$ $<0,05)$ yang artinya ada perbedaan bermakna antara daya sebar dari ketiga formulasi gel ekstrak herba pegagan.

\section{Uji Daya Lekat}

Daya lekat adalah kemampuan sediaan untuk menempel pada lapisan epidermis kulit (Garg dkk., 2002). Tidak terdapat persyaratan khusus mengenai daya lekat sediaan semipadat. Semakin besar kemampuan gel untuk melekat, maka akan semakin baik penghantaran obatnya.

Tabel 4 Hasil Uji Daya Lekat

\begin{tabular}{cccccccc}
\hline Formulasi & \multicolumn{7}{c}{ Hasil Uji Daya Lekat (detik) } \\
\cline { 2 - 7 } & $\mathbf{1}$ & $\mathbf{2}$ & $\mathbf{3}$ & $\mathbf{4}$ & $\mathbf{5}$ & $\overline{\mathbf{x}} \pm$ SD & Sig. \\
\hline FI & 3,16 & 3,20 & 3,12 & 3,42 & 3,32 & $3,24 \pm 0,1241$ & 0,000 \\
\cline { 2 - 7 } FII & 13,60 & 13,20 & 13,56 & 13,41 & 13,37 & $13,43 \pm 0,1602$ & \\
\cline { 2 - 6 } FIII & 25,67 & 25,53 & 25,41 & 25,49 & 25,82 & $25,58 \pm 0,1621$ & \\
\hline
\end{tabular}

Formulasi I memiliki $\mathrm{pH}$ daya lekat rata-rata sebesar 3,24 detik. Formulasi II memiliki daya lekat ratarata sebesar 13,43 detik. Formulasi III memiliki daya lekat rata-rata sebesar 25,58 detik. Hasil uji menunjukkan bahwa signifikansi daya lekat sebesar $0,000(\rho<0,05)$ yang artinya ada perbedaan bermakna antara daya lekat dari ketiga formulasi gel ekstrak wortel.

\section{Uji Viskositas}

Viskositas adalah suatu pernyataan tahanan dari suatu sediaan yang berpengaruh pada sifat alirnya (Martin dkk., 2012). Pengujian viskositas ini dilakukan untuk mengetahui besarnya suatu viskositas dari sediaan, dimana viskositas tersebut menyatakan besarnya tahanan suatu cairan untuk mengalir. Syarat viskositas sediaan gel yang baik adalah memenuhi 
kestandaran viskositas yaitu 2.000-4.000

cP atau 20-40 dPa.s.

Tabel 5 Hasil Uji Viskositas

\begin{tabular}{cccccccc}
\hline Formulasi & \multicolumn{7}{c}{ Hasil Uji Viskositas (dPa.s) } \\
\cline { 2 - 7 } & $\mathbf{1}$ & $\mathbf{2}$ & $\mathbf{3}$ & $\mathbf{4}$ & $\mathbf{5}$ & $\overline{\mathbf{x}} \pm$ SD & Sig. \\
\hline FI & 22,00 & 23,00 & 24,00 & 24,50 & 24,00 & $23,50 \pm 1,000$ & 0,000 \\
FII & 37,00 & 37,50 & 39,00 & 38,00 & 40,00 & $38,30 \pm 1,2042$ & \\
\hline FIII & 72,00 & 73,50 & 73,00 & 73,00 & 73,50 & $73,00 \pm 0,6124$ & \\
\hline
\end{tabular}

Formulasi I memiliki viskositas rata-rata sebesar 23,50 dPa.s. Formulasi II memiliki viskositas rata-rata sebesar 38,30 dPa.s dan Formulasi III memiliki viskositas rata-rata sebesar 73,20 dPa.s. Hasil uji menunjukkan bahwa signifikansi viskositas sebesar $0,000(\rho<$ $0,05)$ yang artinya ada perbedaan bermakna antara viskositas dari ketiga formulasi gel ekstrak herba pegagan.

\section{Uji kecepatan Mengering}

Uji kecepatan mengering dilakukan untuk mengetahui sebarapa lama sediaan masker gel mengering, rentang kecepatan mengering yang baik sekitar 15-30 menit (Vieira, 2009).

Tabel 6. Hasil Uji Kecepatan Mengering

\begin{tabular}{cccccccc}
\hline Formulasi & \multicolumn{7}{c}{ Hasil Uji Cepat Mengering (Menit) } \\
\cline { 2 - 7 } & $\mathbf{1}$ & $\mathbf{2}$ & $\mathbf{3}$ & $\mathbf{4}$ & $\mathbf{5}$ & $\overline{\mathbf{x}} \pm$ SD & Sig. \\
\hline FI & 30,55 & 30,46 & 30,45 & 30,38 & 30,28 & $30,42 \pm 1,000$ & 0,000 \\
FII & 30,00 & 30,10 & 30,36 & 30,40 & 30,85 & $30,34 \pm 1,2042$ & \\
\cline { 2 - 6 } FIII & 31,00 & 30,50 & 30,25 & 30,95 & 30,85 & $30,71 \pm 0,6124$ & \\
\hline
\end{tabular}

Formulasi I memiliki waktu kecepatan mengering rata-rata sebesar 30,42 menit. Formulasi II memiliki ratarata sebesar 30,34 menit dan Formulasi III memiliki waktu kecepatan mengering rata-rata sebesar 30,71menit. Dari ketiga formula memiliki kecepatan waktu mengering melebih besar dari ketentuan. Hasil uji menunjukkan bahwa signifikansi viskositas sebesar $0,000(\rho<$ $0,05)$ yang artinya ada perbedaan bermakna antara kecepatan waktu mengering dari ketiga formulasi gel ekstrak wortel.

\section{Uji Stabilitas Fisik Gel}

Stabilitas didefinisikan sebagai ketahanan suatu produk sesuai dengan batas-batas tertentu selama penyimpanan dan penggunaanya atau umur simpan suatu produk dimana produk tersebut masih mempunyai sifat dan karakteristik yang sama seperti pada waktu pembuatan (Deviarny dkk., 
2012). Uji stabilitas dilakukan pada formulasi terbaik, yaitu Formulasi II. Berikut adalah hasil dari uji stabilitas organoleptis sediaan gel yang dilakukan pada minggu ke-0, 1, 2, 3 dan 4 .

Tabel 7 Hasil Uji Stabilitas Organoleptis Sediaan Gel

\begin{tabular}{|c|c|c|c|c|c|}
\hline \multirow{2}{*}{ Organoleptis } & \multicolumn{5}{|c|}{ Minggu ke- } \\
\hline & $\mathbf{0}$ & 1 & 2 & 3 & 4 \\
\hline Warna & orange & orange & orange & orange & orange \\
\hline Aroma & $\begin{array}{c}\text { Khas } \\
\text { simplisia } \\
\text { wortel }\end{array}$ & $\begin{array}{c}\text { Khas } \\
\text { simplisia } \\
\text { wortel }\end{array}$ & $\begin{array}{c}\text { Khas } \\
\text { simplisia } \\
\text { wortel }\end{array}$ & $\begin{array}{c}\text { Khas } \\
\text { simplisia } \\
\text { wortel }\end{array}$ & $\begin{array}{c}\text { Khas } \\
\text { simplisia } \\
\text { wortel }\end{array}$ \\
\hline Konsistensi & Kental & Kental & Kental & Kental & Kental \\
\hline
\end{tabular}

Sediaan Gel diperoleh hasil bahwa secara organoleptis sediaan gel tetap stabil saat penyimpanan pada suhu kamar selama 4 minggu. Sediaan gel tetap berwarna oranye, aroma khas simplisia wortel dan memiliki konsistensi yang kental.
Berikut adalah hasil dari uji stabilitas sediaan gel yang dilakukan pada minggu ke-0, 1, 2, 3 dan 4 yang terdiri dari rata-rata hasil uji $\mathrm{pH}$, daya lekat, daya sebar dan viskositas

Tabel 7 Hasil Uji Stabilitas Sediaan Gel

\begin{tabular}{|c|c|c|c|c|c|c|c|}
\hline \multirow[t]{2}{*}{ Stabilitas } & \multicolumn{5}{|c|}{ Minggu ke- } & \multirow[t]{2}{*}{$\overline{\mathbf{x}} \pm \mathbf{S D}$} & \multirow[t]{2}{*}{ Sig. } \\
\hline & $\mathbf{0}$ & 1 & 2 & 3 & 4 & & \\
\hline pH & 6,70 & 6,75 & 6,75 & 6,80 & 6,90 & $6,78 \pm 0,0596$ & 0,671 \\
\hline $\begin{array}{c}\text { Daya Lekat } \\
\text { (detik) }\end{array}$ & 13,43 & 13,43 & 11,58 & 10,56 & 9,38 & $11,68 \pm 1,7804$ & 0,000 \\
\hline $\begin{array}{c}\text { Daya Sebar } \\
(\mathrm{cm})\end{array}$ & 5,23 & 5,28 & 5,35 & 5,39 & 5,51 & $5,35 \pm 0,1078$ & 0,000 \\
\hline $\begin{array}{c}\text { Viskositas } \\
\text { (dPa.s) }\end{array}$ & 38,30 & 37,60 & 37,20 & 36,50 & 35,90 & $37,10 \pm 0,9354$ & 0,000 \\
\hline
\end{tabular}

Hasil Uji Stabilitas Sediaan Gel diperoleh bahwa berdasarkan nilai signifikansi dari uji daya lekat didapatkan nilai signifikan sebesar 0,000 $(\rho<0,05)$ yang artinya ada perbedaan bermakna antara uji stabilitas daya lekat pada setiap minggunya. Berdasarkan nilai signifikansi dari uji daya sebar didapatkan nilai signifikan sebesar 0,000 $(\rho<0,05)$ yang artinya ada perbedaan bermakna antara uji stabilitas daya sebar pada setiap minggunya. Berdasarkan nilai signifikansi dari uji viskositas didapatkan nilai signifikan sebesar 0,000 $(\rho<0,05)$ yang artinya ada perbedaan bermakna antara uji stabilitas viskositas 
pada setiap minggunya. Berdasarkan nilai signifikansi dari uji $\mathrm{pH}$ didapatkan nilai signifikan sebesar $0,671(\rho>0,05)$ yang artinya ada perbedaan tidak bermakna antara uji stabilitas daya lekat pada setiap minggunya.

DAFTAR PUSTAKA

Deviarny C., dkk., 2012., Uji Stabilitas kimia natrium Askorbil Fosfat Dalam Mikroemulsi dan Analisisnya Dengan HPLC., Jurnal Farmasi Andalas

Garg, A., Aggarwal, D., Garg, S dan Sigla, A.K. (2002). Spreading Of Semisolid Formulations: An Update Pharmaceutical Technology. India: Panjab University..

Vieira, R. P. 2009.Physical and Physicochemical Stability Evaluation of Cosmetic Formulations Containing Soybean Extract Fermented by Bifidobacterium animalis.

\section{KESIMPULAN}

Berdasarkan hasil dalam penelitian ini dapat disimupulkan, bahawa formulasi dengan konsentrasi ekstrak wortel 5,0\% mempunyai hasil yang sangat baik dengan berbagai pengujian.

Brazilian Journal of Pharmaceutical Sciences

Voigt, R., 1995. Buku pembelajaran Teknologi Farmasi, edisi 5, diterjemahkan bahasa inggris oleh Neorono, S. Gajah madaUniversity Press, Yogyakarta

Voigt. R., 1984, Buku Pelajaran Teknologi Sediaan Farmasi, diterjemahkan oleh Soendani, N. S dan Mahtilda, B. N., 202-207, 220225, Gadjah Mada University Press, Yogyakarta.

Wasitaatmadja, S. M., 1997. Penuntun Ilmu Kosmetik Medik. Universitas Indonesia (UI-Press). Jakarta. 